patent, to be either oxide of lanthanium and zirconium or oxide of yttrium and zirconium. 'The latter may be replaced by a quantity of erbinm free from other elements belonging to this group of rare oxides and the former by oxides whereof the elements belong to the group of rare earths which are found in cerite. placed by magnesia.

In the cotton or woolmpregnated with a solution of nitrate or acetate of one of the before mentioned substances; and the tissue having been carbonized, there is left behind, as residue, the earthy matter in the there is oft behing given to the tissue. Consequently, without any special manipulaits incandescent material.

Dr. Auer does not confine himself to the cone-shaped cylinder; but in the event of other forms being adopted he advises that the more exposed parts of the material should be strengthened by a solution of nitrate of mag nesia and alumna. Such is briefly the new incandescomplete revolution in the gasindustry.-Jour. of Gas Lighting.

PHOTOGRAPHIC REPRODUCTION OF THE

LUMINOUS EFFECTS OF ELECTRICITY

WITHOUT THE USE OF ORDINARY PHO-

TOGRAPHIC APPARATUS. By Dr. M. BOUDET.*

GeNTLEMen : You will, perhaps, remember that it will soon be two years ago that I had the honor of showing you a series of experiments relating to the electric conductivity of rarefied gases. The results of Edlund as to the conductivity of a vacuum; besides which, they rendered evident the place of formation of the electromotive force that occurs in a glass vessel that contains no air and is being traversed by a current of high tension. From this particular point of view, the experiments performed before you gave a slightly by Mr. Edlund. At present. I shall set the advanced principle aside, and prest, you in mind of one of the experiments-the only one that has a direct bearing on the new facts that I am going to talk to you about.

Three glass spheres, of exactly the same capacity and of equal thickness, were traversed at one point of their surface by a platinum rod whose free extremity reached the center of the sphere, and whose externa portion was covered by a metal ball. One of these metal, and the third contained a perfect vacuum nally, the whole three were covered with tin foil over two-thirds of their external surface.

Thus we had three condensers of the same surface, whose proper capacity we compared. Now, the spark resulting from the discharge of them differed much was each other. That of the sphere containing wate was accompanied with a sharp crackling sound (Fig. 1). That of the sphere containing Dutch metal was short-

apparatus, but obtained merely imperfect results. tion to the study of the effluvium, and of the discharge More recently, I have tried the experiment anew by of the Voss machine. 'The photographic results are

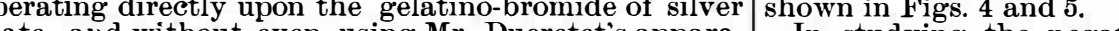
In studying the negatives, especially the one that
us. A photographic plate having been laid down flat,

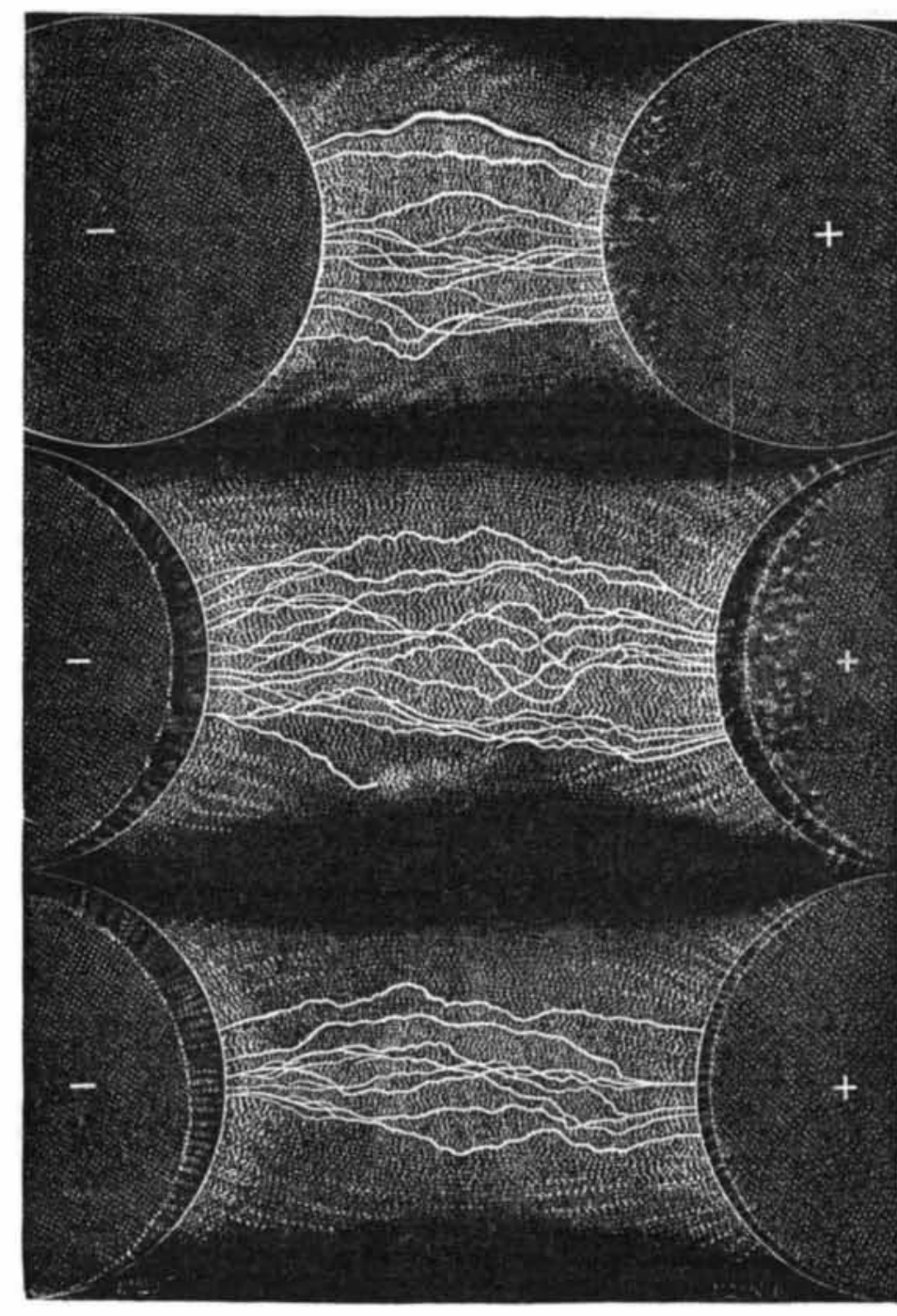

Fig. 5.

ensitized side up, I placed two pieces of silver (a five an imprint of their effigy. Struck by this fact, I placed apart. I chate ting its external covering in communication with the moved all around it an exciter connected with the
ive franc piece, I placed the button of the lower rod other pole of the machine. The piece was thus sur-

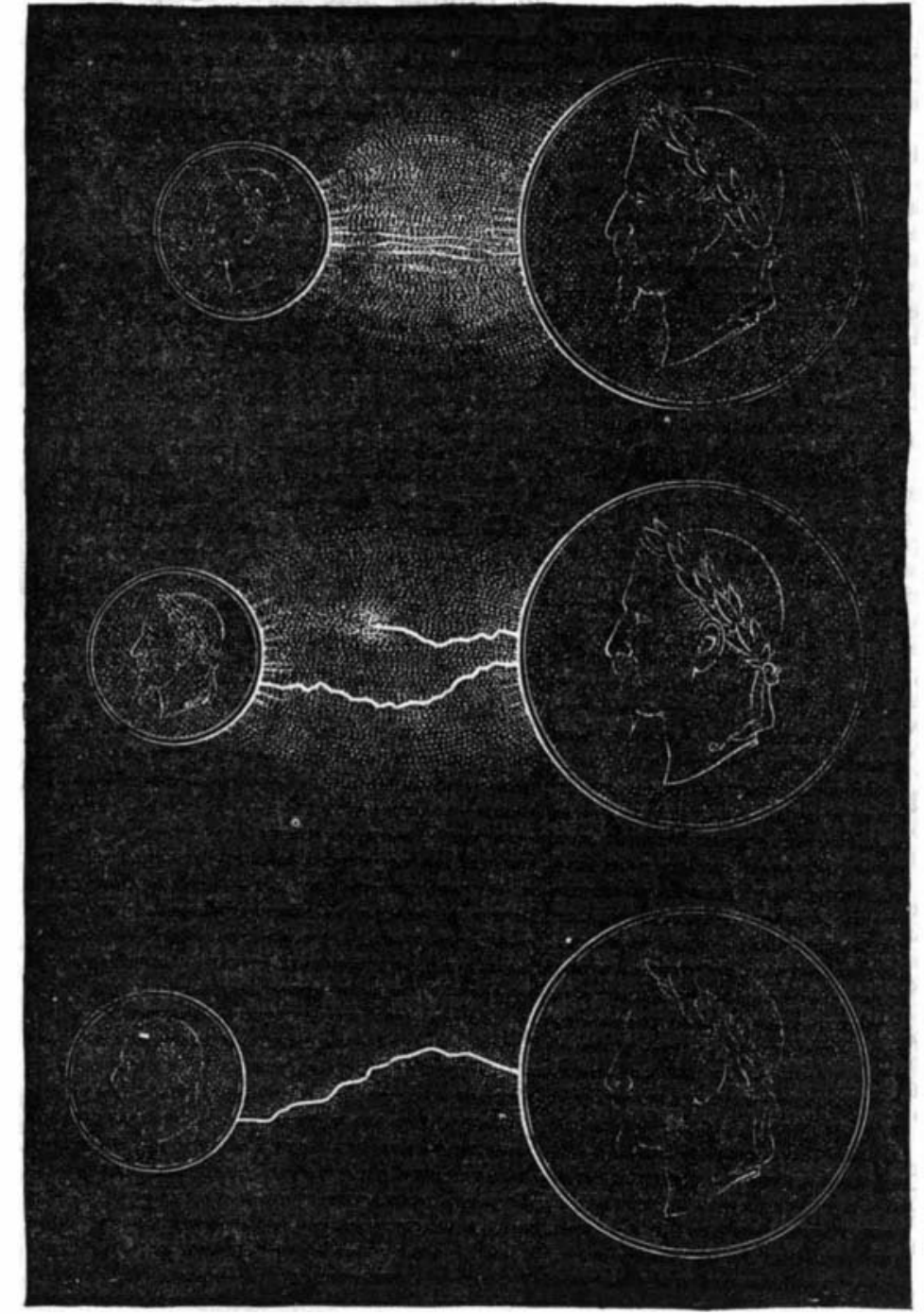

FIG. 4.

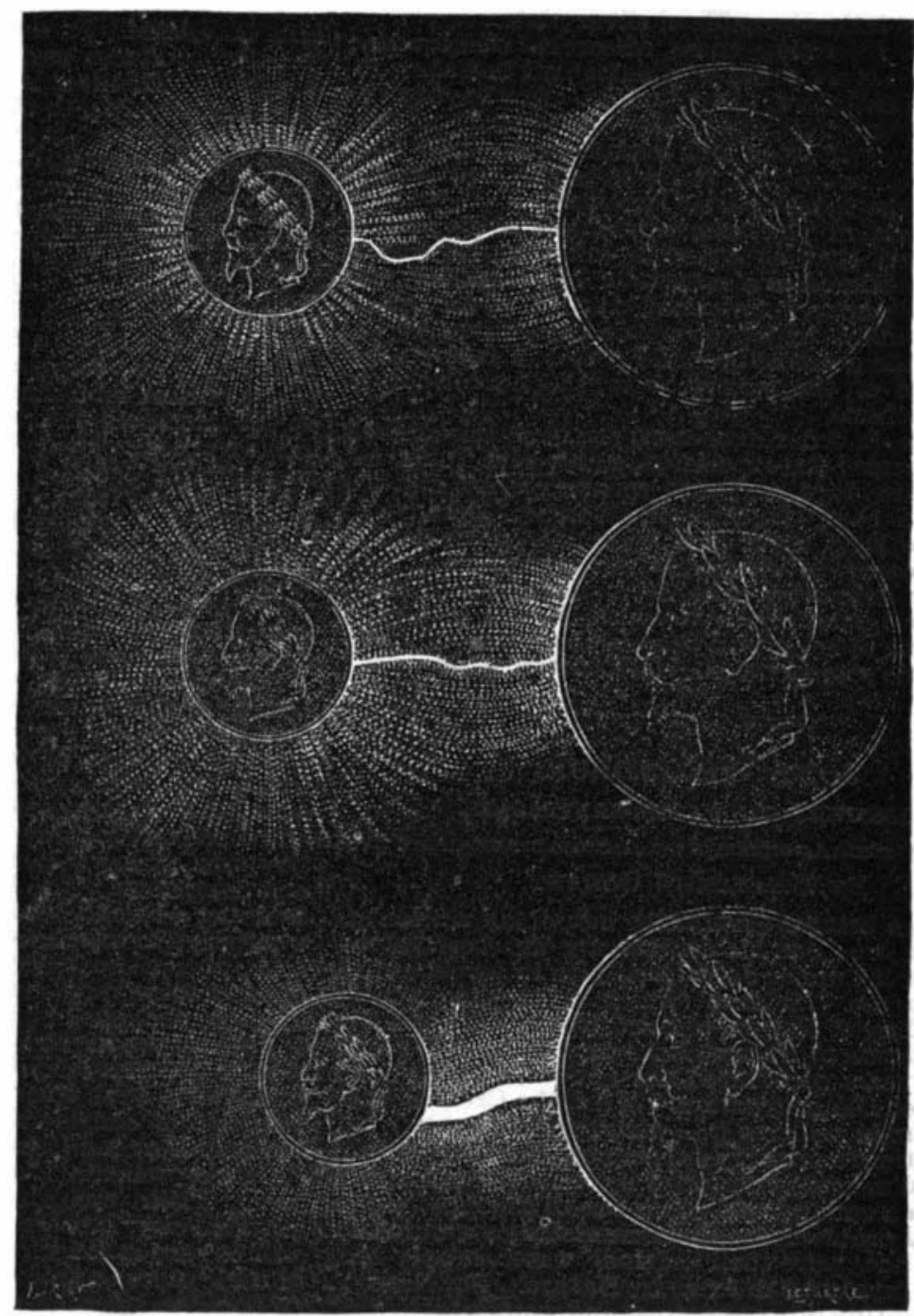

Fras. 1, $2,3$.

er, wider, more brilliant, and less sinuous, and the upon the fifty centime coin. A spark at once leaped rounded with an aureola of sparks nearly an inch in

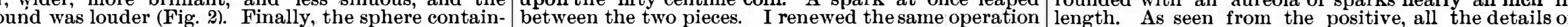
ing a vacuum furnished a dazzling, very short and with each kind of condenser, and then put the plate into the usual developing and fixing baths. Figs. 1, 2

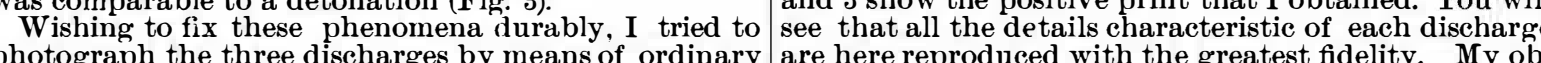
photograph the three discharges by means of ordinary are here reproduced with the greatest fidelity. My object was attained. the piece were perfectly reproduced. To interpret the phenomenon was not one of the easiest things to do. Was the sensitization of the silver bromide to be attributed to a chemical effect of electri-
city, to the illuminating power of the sparks, or to a mechanical action analogous to that which occurs in 
A priori, it seerned to me possible to discard the
intervention of a direct chemical effect, and this opinThere now remained the meehanical and luminous actions. The following are the experiments that allowed me to solve the problem.

Whece, we see that the salient parts of the effigy come
piect taken by ordinary apparatus. Everything, therefore, pointed toward the taking of a counter proof by means of a matrix in metal. I there
You will see city of Padua.

You will see that, this time again, the impressing of an ordinary photograph, and the depressions came out in black in the positive proof. Pushing my investiga-
tions still farther, I drew a figure with common in
on very thick paper, which I afterward interposed beon very thick paper, which I afterward interposed be
tween a metal disk and the photographic plate. Th
time again the reproduction was effected as in the case time again the reproduction was effected as in the case of an ordinary photograph; and what is particularly
interesting here is that, although the paper, despite its
thickness, was traversed by sparks at several portions thickness, was traversed by sparks at several portions
of its periphery, the drawing was not reproduced at of its periphery, the drawing was not reproduced at call in a mechanical action of the discharge in order to On another hand, if this latter effect is really the consequence of the illuminating power of the discharge,
we ought to be able to increase the effect obtained by increasing the light under the design to be reproduced,
that is to say, by laying the plate on a mirror. Experi-
ment fully decided in favor of such a hypothesis, for the negatives became much sharper, and the contrasts of light and shade much more clearly defined.
Besides, I thought that the effluvium, bec

violet tint, must have a higher actinic power than the
white light of the spark, and the result fully answered my expectation. impression made on the silver bromide was due to the
luminous action of the electric effiuvium, and that such action reached its degree of maximum when it was reflected by a mirror, it seemed to me possible to repro-
duce any object whatever, metallic or not. I then placed upon a sensitized plate an ordinary photographic and afterward passed the effiuvium over its entire
periphery. In this way I obtained a reproduction of the photograph

far from being as perfect as proof which I show you is far from being as perfect as the others; but this is due
to two causes, viz., first, I am only a bad apprentice in photography, and do not yet know what quantity of and second, as the card was varnished, there was con-
siderable glittering on its surface under the influence
of the obliquely reflected light. I believe that this latter-cause plays a large part in the relative darknes of this reproduction. However this may be, the princi-
ple exists. The different prints that I have submitted nation produced by the electric effiuvium, and reflected by a mirror, permits of reproducing with all its details, whether sunk or in relief, any plane object whatever Perhaps, on pushing these researches still further
we shall reach truly practical results, and find some in
dustrial applications of the principle dustrial applications of the principle. Not having the necessary leisure to continue the experiments myself,
I present you with these first tentatives, in order that those of you whom the thing interests may renew
them and make them entirely successful.
In the train of this communication, some persons In the train of this communication, some person
have objected that as common ink contains iron it
might be considered as a conductor of electricity, and that as the paper is prepared with a silver salt, a
catalytic (?) effect might occur on the contact of the catalytic (?) effect might occur on the contact of the
paper with the gelatino-bromide plate. I believe that
the presence of the varnish is sufficient to dispose of uch a hypothesis.

Meanwhile, in order to content the most incredulous,
I have performed the experiment anew with India ink I have performed the experiment anew with India ink
and pastel drawings, and with various papers, and the shall before long show that there is even no need of having recourse to electricity for reprod ucing any away with all questions as to conductivity, and proving that light alone acts in these phenomena of dire
photographic reproduction.-La Lumiere Electrique.

\section{JOB'S CONUNDRUM.}

A LECTURE ON WATER-SANITATION.

Before the Polytechnic Association of the American Institute, April 22,'86. By William C. Conant.

"WHo can bring a clean thing out of an unclean?"

Job gave it up; but his conundrum has been solved. for him to see. Science (which is nothing but an ly but imitation of Nature) have in the course of four thousand years penetrated the secret, and they have also bettered the instruction. What the Creator alone But to extract a pure crystal element from the solution
of mud and mortality supplied by our city aqueducts is more than a conundrum. It is one of the most urgent of practical problems for all accumulating communities,
no matter how pure their original water supply may
have been furnished to them by Nature. For Nature water-sanitating processes, greatand wonderful as they water-sanin to be overpowered as soon as multiplying men and domestic animals begin to crowd together beds with excess of organic refuse. The problem then
instantly arises : how to bring again the clean thing
out of the polluted. Pestilence after pestilence presses the question, from generation to generation, until at populations becomes saturated with germs of malig nant disease, which are drained thence into streams
and springs, and carried by them to all who drink of

That air and water are the grand carriers of diseas and death is now a truism. It is settled that their imare not due to individual imprudence or transgression to prove this, but their real office at the present day
would be merely to freshen a conviction that has long been established in every intelligent mind. While Dr. Farr was Registrar-General of Vital Sta-
tistics for the City of London, his tables showed that whenever the temperature of the dirty Thames water
was over sixty degrees, the deaths from diarrhoic diseases in the district dependent on the river water were
three times more numerous in proportion to the population than in the other districts. As was stated in a
report from the medicalmembers of the Newark Board report from the medical members of the Newark Board
of Health, "The majority of sanitarians agree tha water is the common carrier of contagious diseases scourges of mortality-Asiatic cholera and typhoid Devers."
During the visitation of cholera in London, one sid of a street was ravaged, while the other side, supplied nent hygienist says that the always floating products
of the decomposition of leaves, wood, etc., and all forms of vegetable matter, are the most frequent causes
assigned for epidemies of typhoid fever.
The late terrible devastations of cholera in Spain covered in general only the territory just previously covered by unprecedented floods, which left in their matter all over the surface of the country.
The recent frightful epidemic in Plymouth, Pa., was The recent frightful epidemic in Plymouth, Pa., was
literally washed down into the devoted village by
clear mountain stream, from the dwelling of a single sick family. The report on the Croton water by Elwyn
Waller, Ph.D., chemist, 'to the Board of Health of New York city, states the chief dangers in drinking
water to be the nitrogenous constituents that predom nate in the excreta and decomposing carcasses of antory that supplies the city with water, together with a matter in the vegetable decay that everywhere is carried into the streams, besides lower forms of vegetable
life which are never absent from water except possibly rare cases in artesian wells.

is a false security in the use of waters on this subject yet proved pestilent, and that are therefore assumed to
be safe for the future also. Nothing could be more opposed to fact, and to fact of constant recurrence, tha
such an inference as this. The Plymouth epidemi such an inference as this. The Plymouth epidemic,
just mentioned, and a precisely similar case in Lau-
sarne, Switzerland, flowed from sources the least probable, among the conditions of water supply, that could streams of rare purity suddenly contaminated, through the deadliest germs of pestilence. The same thing may
happen, in spite of all precautions, to any stream, happen, in spite of all precautions, to any stream,
spring, or well on which families and even cities ar spring, or well on which families
depending for this vital element.

\section{THE DANGERS OF DRINKING}

grow constantly with the growth of population
"Life eminent creates-the shade of death."

Life is suicide. It not only wears itself out, it continually produces and uses the means of its own de
struction. This fact is most remarkable with respec to cumulative life, or the community of man, in its col-
ective operation. It is not necessary to go to large
cities for the most striking illustrations of the process. A single house far up on a mountain side, by a pure stream, has in repeated instances, such as I have alnear. The natural conditions of existence were the engendered dangers of which Nature knows nothing. And so it may happen at any time and any place,
where human life accumulates and works unguardedly where human life accumulates and works unguardedly the germs of death.

Thus indeed it does happen, here and there, all over
the world. A woman from a cholera distriet washer her clothes in a stream in Spain, and half depopulated above. Modern news collection discloses these sudde
epidemics with appalling frequency, but their frequency is nothing new under the sun.
To quote Professor Cook, of Rutgers College, Sta Geologist of New Jersey : At first, when a country is
thinly settled, we get pure water from wells; but asth tories, the earth gradually becomes filled with thei accumulated impurities. Thenceforward, the rainfall and dangerous. The same is true of springs. Streams
draining a thickly settled country, or a farming region
where fertilizers are used, and where Paris green and where fertilizers are used, and where Paris green and
other poisons are freely applied to destroy insects, must
often become very much contaminated. The natural often become very much contaminated. The natural
filterage and chemistry of purification, which suffices to remove the impurities coming from a sparse popula-
tion, is overpowered by the enormous filth of great multitudes, with their often noxious manufacturing re-
fuse, and of course fails to do a work for which it measure is so inadequat
Driven wells

Driven wells have no such exemption as some sup-
pose. Their water may be good at first, even in pose. Their water may be good at first, even in a
crowded city, but the inevitable filth of the situation
will be sure at length to make its way down the sides will be sure at length to make its way down the sides
of their pipes to the water courses which they drain. Of four samples of driven well water submitted t ed with scum, and gave out an offensive odor. Mor connection with the subterranean water, unsuspected at a great distance from the point where it is tapped by
well. Within my own knowledge, a driven well $40 \mathrm{ft}$. apparently from the vaults and cesspools of a hotel epidemic repute a mile away on the mountain. The poisons to which it was applied. All it did was to
identify with a poisonous source the water of that deep
and remote well, and that it did unmistakably.
Until lately, the most of these local epidemics were
assed among the inscrutablemysteries of Providence. Now, they are clearly known to flow from fountains poisoned by the disorders and mistakes of man. The
channels that convey these human mischiefs are often subterranean and long, defying scrutiny, and consequently their sources are only to be suspected, not di malignant disease falls upon a community or a family we now look with certainty for the cause in some conlife, especially water. If we cannot discover it, more's The inference from all this multitude of facts is irresistible, that plagnes are possible at all times and
places, and are actually occurring, from time to time, supply of drinking water that is not systematically Theoretically, contaminated waters are classed amons avoidable causes of disease, but practically they have been unavoidable hitherto for nearly all mankind. It
is from this cause that sanitary improvement lags so
far behind the other arts of life in this great age of far behind the other arts of life in this great age of
progress. In the matter of life, health, and longevity, man has not yet begun to reap the fruits due to him
from the progress of science and arts. Not until the present hour have the dangers and devastations of
contaminated water met with their match among the contaminated water met with their match among th
masters of applied science. Hitherto, the invention of apparatus adequate to the effectual and economical
purification of all waters, in all situations, and on the large and continuous scale indispensable to a real sanitary revolution, has been delayed. This now happily those who have the ear of the public to rouse the
public mind out of the apathy of discouragement on public mind out of the apathy of discouragement on of mortality and pestilence, now preventable, to which
hopeless use and wont have hardened us. It is time for humanity to lift up its head, and begin to aspire, than it has ever seriously imagined heretofore.
Furthermore, there is an opinion to be corrected, but which has been industriously fostered (from a motive
which was gond in time past) by the sanitary grides of
the people themselves, namely, that dirty water is not necessarily unwholesome. People in cities especially have needed encouragement to drink, and to drink could have, and it was wise to try to shut their eyes Commercial considerations have powerf ully influenced evils of a water supply for which they could see no remedy. But common sense needs only to be left to t with instinctive loathing, and it is decidedly "cheeky" in doctors to tell us that we may as well swallow it as dirty water, to say nothing of poisoned water, whether on the Mississippi, the Ohio, the James, or any other muddy stream; on water courses lined with manuin capitals like New York, Boston, Philadelphia,
Washington, or Chicago, whose costly water supplie Washington, or Chicago, whose costly water supplies every year from the complaisant medical servants of such municipalities.

The announcement deserves to command universal attention-water purification is now a perfected art. elastic scale of quantity and rapidity; done without
interruption; done without end; and done almost without practical increase of
perhaps two or three per cent

You can see all this for yourselves on any day and
every day of the year, in Raritan, Somerville, or New Brunswick, N. J. . in great manufacturing establishneighborhood ; and insuch cities as Chicago, Cincinnati,
and others, in the West; and at the late Exposition at New Orleans the muddy Mississippi was transformed, into crystalline water rivaling for purity and brilliancy the water of the most famous bleachery springs, and
from which had been separated by accurate demontration, ten tons a day of solid filth!

THE ESSENTIAL PRINCIPLES OF THE OPERATION are four, three of which are exact eopies from Nature,
and the other is an improvement on Nature's less practicable device. First, the microscopie impurities that and these are the most corrupt and dangerous of all must be detached from their state of solution or int
mate diffusion, and conglomerated in particles not too minute to be stopped in the meshes of a fine bed of
sand and coke. Nature has done exactly this thing in
every drop of pure spring or well water in the world, and has done it in exactly the same way that the an ANSWER : All soils contain traces, usually very minute, of the salts of potassium, aluminium, calcium
or iron. Every drop of water passing through the soil is affected by an inconceivably small quantity of one
or more of these salts. The effect of the infinitesinal dose is among the wonders of chemistry. It seizes
upon every atom of soluble impurity diffused in the upon every atom of soluble impurity diffused in the sticks them together so that they cannot pass through the great filter beds of sand and porous seams of rock
that Providence has arranged for the sanitation of drinking water. These metallic salts together with
the organic and other impurities that they have collared and corraled, are thus entirely detained for play a second time a part of utility wondertion to their quanty.
The double sulphate of potash and alumina commonly called alum, is a pungent and astringent salt,
which few except children enjoy tasting. It is not
poisonous, and yet, to keep it in water pitchers, as
many of the good people of Richmond, Va, are said to poisonous, and yet, to keep it in water pitchers, as
many of the good people of Richmond, Va., are said to
do, in companion chunks to their ice, could not be recommended for a salutary effect on the alimentary
canal, in the long run. But why do they do this 